\title{
El gobierno del arte. Problemas actuales de las políticas culturales*
}

\author{
Agustín Lucas Prestifilippo**
}

\begin{abstract}
Resumo: En este artículo nos proponemos analizar las dimensiones de la interrelación existente en la actualidad entre la cultura artística y las políticas culturales a partir del caso de algunos fenómenos de la literatura Argentina. Nos preguntamos por los modos de concebir teóricamente las tensiones entre las búsquedas estatales de regular normativamente la práctica artística y las formas de reacción de parte de su destinatario. Dado que un abordaje abstracto se vería imposibilitado de acceder a las complejidades de las distintas experiencias posibles, indagamos los antecedentes históricos del vínculo entre las prácticas artístico-literarias y el diseño e implementación de políticas públicas en dos períodos: la conformación del Estado nacional a fines del siglo XIX (I) y la época de las vanguardias de los años sesenta y setenta (II). Este rastreo nos permitirá reconstruir una aproximación teórica a los conflictos subyacentes a la idea de justicia en los debates entre el Estado y las prácticas literarias (III). Finalmente, extraemos algunas consecuencias de estas experiencias históricas para el estudio de los retos actuales del gobierno democrático de la cultura artística (IV).
\end{abstract}

Palavras-chave: Cultura artística. Políticas culturales. Justicia social. Literatura Argentina. Estado.

Las iniciativas estatales tomadas a lo largo de los últimos años en relación a la legislación de la cultura argentina han interpelado al estudio de políticas culturales al seguimiento detallado del proceso de su implementación. Si a fines de los años ochenta y a lo largo de los años noventa los reclamos en torno a una democratización de las comunicaciones, al reconocimiento de las identidades de género, y a la reactivación de la memoria a propósito del trauma de la última dictadura militar, colocaban al pensamiento frente al objetivo de trazar las líneas básicas de aquello que deberían regular leyes que procuren promover la democracia cultural, en nuestros días la tarea parecería haberse desplazado sutilmente. Se deja ver un nuevo horizonte de preguntas, motivado, no caben dudas, por la receptividad de las instituciones públicas para muchas de aquellas reivindicaciones colectivas pero también por la siempre renovable efervescencia de la esfera de discusión política.

* Agradezco a mis compañeras/os del grupo de investigación PIP - Conicet "Problemas de la democracia argentina en el período de la post-convertibilidad. Transformaciones socioeconómicas y reconfiguraciones ideológicas", sin cuyas fructíferas discusiones varios planteos de este trabajo no hubieran sido posibles

** Conicet - IIGG / Universidad de Buenos Aires. Doctorando en Ciencias Sociales (UBA) 
En una entrevista a Sergio Raimondi publicada recientemente, el poeta bahiense precisa este horizonte en los términos de un genuino problema:

\begin{abstract}
La cuestión sería: ¿por qué, en vez de estar trabajando ahora en una poesía donde el Estado forme parte de la perspectiva, estoy directamente dentro de él escribiendo parte de su prosa administrativa? Para mí porque este presente habilita a darle a una experiencia como la de esa poesía que escribí, un valor de uso político en términos más específicos (VV.AA.: 2013: pp. 76 y 77).
\end{abstract}

Quien escribió un poemario tan significativo para la lectura a contrapelo de la hegemonía neoliberal en Argentina como Poesía civil, se desempeña hoy como Director del Instituto Cultural de Bahía Blanca. Ese desplazamiento no puede soslayarse: "sin duda", sostiene el poeta devenido funcionario estatal, "hay una diferencia cualitativa entre el verso y el expediente" (p. 76). Sin embargo, aunque el género de su escritura se haya orientado hacia la "prosa administrativa", el poeta no ha cesado de escribir. Esta continuidad es la que habilita otorgarle a la poesía "un valor de uso político en términos más específicos". Ahora bien, ¿cuál es el sentido de esta continuidad?, ¿es posible formular interrogantes desde la perspectiva del arte de la poesía y, al mismo tiempo, desde la perspectiva del Estado sin que esto implique pérdidas de alguna de ambas partes? Entre la poesía y la prosa administrativa del Estado parecería mostrarse una extraña reversibilidad de la cual a la vez que posibilitaría transiciones recíprocas, ellas no habilitarían entenderlas en términos de traducibilidad. ¿En qué consiste entones este valor?, ¿cuáles son sus efectos para los actores involucrados?

La crítica de la cultura se ve requerida a reflexionar sobre las consecuencias de la aplicación de normas en su terreno. Lo que significa: indagar acerca de cómo aquellas deberían ser implementadas y cuáles serían las consecuencias no previstas de esa ejecución. Se sigue de esto que únicamente una reflexión situada, que trabaje sobre y desde los casos concretos, podrá proceder satisfactoriamente. En este trabajo desearía plantear algunos de estos interrogantes a partir de una historia de las ideas relativas a un caso bien específico; a saber, la gestión de las prácticas artísticoliterarias.

\title{
I.- A propósito de una gran división
}

En esta formulación se vuelve necesario realizar una diferenciación. De otra forma, se presupondría una imagen purista en donde la cultura artística aparecería como un "refugio" aislado de las relaciones de poder y los contextos históricos de lucha social por la redistribución de los recursos económicos y simbólicos. Efectivamente, el singular presupone un campo de homogeneidad de difícil rastreo en el plano de las prácticas concretas. Pues es sabido que en la modernidad capitalista la cultura artística se ha debatido entre dos modelos diferentes, incluso, antagónicos. Aquel que tradicionalmente se ha reconocido como digno de valoración, un arte "elevado". El otro modelo es el que, precisamente por su accesibilidad general, ha visto debilitada su legitimidad en la comparación normativa: la llamada "cultura de masas". Con inteligencia, Andreas Huyssen (2006) ha destacado los aspectos dilemáticos de esta gran división. Principalmente, el hecho de que -como aquella 
"india rubia" de "Historia del guerrero y de la cautiva"- al nacer bajo una estrategia de exclusión, la alta cultura modernista siempre tuvo un lastre, no siempre consciente ni siempre declarado, de atracción por debajo de la angustia de ser contaminado por la cultura de masas.

En la cultura latinoamericana, según Ángel Rama, la división entre modernismo y cultura de masas es la traducción, al interior de la cultura artística, del proyecto político modernizador de las élites gobernantes. Su programa fundacional, dice el ensayista uruguayo, han instalado un despotismo ilustrado "sin intentar recoger de los hombres que la componen esos valores que conducen sus formas culturales específicas y tradicionales". En esta lectura, la cultura letrada "fue" desde los tiempos de la monarquía absoluta "una cultura inducida que se prevaleció del extraordinario aparato educativo para transmitir la ideologización de las élites". Como resultado, el modelo del alto modernismo no es sino la imposición autoritaria de una élite, bajo cuya fuerza "la pluralidad de culturas sometidas que de hecho integran la nacionalidad no ha sido reconocida ni han adquirido fuerza sus variadas demandas a integrar una cultura auténticamente nacional" (RAMA, 1980: pp. 8-9).

De esta manera, es posible rastrar el programa modernizador de las élites liberal-conservadoras de fines del siglo XIX en dos condiciones históricas de posibilidad que las anteceden: las exigencias de una administración colonial eficaz en el ejercicio de su poder y los requerimientos de evangelización de una renuente población indígena. Estos requisitos para la consolidación del poder real de la monarquía se asentaron en lo que el autor denomina ciudad real. Y fueron los letrados urbanos aquellos encargados en cumplir con ellos. Por lo tanto, en el interior de la ciudad real "siempre hubo otra ciudad, no menos amurallada ni menos sino más agresiva y redentora, que la rigió y la condujo. [...] En el centro de toda ciudad, según diversos grados que alcanzaban su plenitud en las capitales virreinales, hubo una ciudad letrada que componía el anillo protector del poder y ejecutor de sus órdenes" (RAMA, 1998, p. 32).

En la Argentina, en los años que abarcan el período de 1880 a 1912, encontramos una muy curiosa lógica de intercambio entre modernización literaria entendida como profesionalización de los escritores- y modernización político-estatal. "La coalición cultural y literaria de 1880 es [...] una coalición estatal, quizás la primera" (LUDMER, 1999, p. 25). Esta coalición adoptó el carácter de una relación funcional en la medida en que los requisitos de un Estado argentino en vías de formación condujeron su atención a una cultura moderna que diera el cemento a partir del cual las identidades y las prácticas queden unificadas en una noción compartida de ciudadanía y en un conjunto de creencias nacionales, las cuales -según el diagnóstico de los promotores y funcionarios estatales- solamente estos intelectuales eran capaces de forjar. En este sentido, las consecuencias político-culturales de esta "república de las letras" se vuelven claras.

Las políticas culturales y educativas de ese Estado identifican tales discursos y representaciones en la producción y transmisión de una narrativa de la nación que puede caracterizarse como invención de [...] ritos y modelos de subjetividad, pero son a su vez los nuevos escritores quienes refuerzan esa identificación o lisa y Ilanamente intervienen para legitimarla; de ese modo, tales escritores desempeñan en efecto en muchas ocasiones, e imaginan desempeñar, la ejecución de esas políticas culturales y educativas (DALMARONI, 2006, p. 39). 
Sin embargo, la división entre los modelos de la alta cultura letrada y de la cultura oral no adopta la disposición de una coexistencia pacífica sino que resulta de una oposición binaria jerárquicamente ordenada. En ella uno de los términos pretende gobernar al otro. Es por ello que, al mismo tiempo en que estas políticas públicas eran diseñadas e implementadas en beneficio de ciertos sectores de la sociedad con anhelos de producción cultural, otras políticas se propusieron contener el avance de literaturas que promovieran tradiciones, emblemas, mitos históricos y políticos alternativos a los fomentados por el Estado argentino (PRIETO, 1988, p. 14).

La división sería el resultado de una hegemonía simbólica de un grupo de poder, el cual, en "muchos campos de actividad al mismo tiempo" hace de la "estereotipación [...] parte del mantenimiento del orden social y simbólico. Establece una frontera simbólica entre lo «normal» y lo «desviante» (HALL, 2010: pp. 430-431). Un claro ejemplo de esta práctica de estigmatización como estrategia de sometimiento simbólico y social lo demuestra cierta línea de la tradición de la literatura gauchesca en Argentina, desde los textos de Hidalgo hasta La vuelta del Martín Fierro. ${ }^{1}$

En el caso del Borges criollista de los años veinte, esta práctica es interrogada a través de la incorporación de las flexiones, los ritmos y el léxico de la lengua oral en un plano de parodia. En "Dos hombres pelean", por ejemplo, se entreveran a cuchillo el Norte y el Sur de Buenos Aires: El Mentao y El Chileno. De un duelo semejante uno perece y el otro reivindica su valor: "No sirve sino pa juntar moscas, dijo uno que, al final, lo palpó. Murió de pura patria; las guitarras varonas del bajo se alborozaron" (BORGES, 1993, p. 128). Al mismo tiempo en que la escritura se emplaza en una zona "de orientación más depreciativa que topográfica", acaso para ennoblecerla en la formación de una leyenda que la colme, la narración le otorga un carácter problemático. En el cuento es El Chileno quien cae ante el hachazo del cuchillero de Palermo. El discurso indirecto coloca a la oralidad suburbana en el centro de la voz del narrador; y de esta forma se hace visible el acoplamiento que se pretende articular. Pero, justamente por esto, la narración se vuelve afilada como un cuchillo; en última instancia, mortal. A esto se refieren algunos comentadores como la estructura refleja de la literatura de Borges. En cuentos posteriores como "Hombre de la esquina rosada" o "El sur" la literatura demuestra el momento de violencia simbólica inevitable que se produce en el encuentro de la cultura letrada y la cultura oral. En la fascinación por la entonación criolla se muestra, por la distancia siempre presente que su lectura promueve, los dramas de la representación del escritor: hablar por el otro. ${ }^{2}$

Como puede observarse en el recorrido que va de Hidalgo a Borges, pasando por Hernández, es posible demostrar hasta qué punto la declaración de Ángel Rama en torno a la contraposición simple entre cultura de élite y cultura de masas exige ser

${ }^{1}$ Josefina Ludmer (2000) ha analizado los ejercicios de poder que el vínculo entre cultura letrada y cultura oral suponen. El género gauchesco presupone un uso letrado de la cultura oral. Pero no solamente: "Por ese uso del cuerpo, que separa a los gauchos de un campo [el de la marginalidad], al de batalla [de la independencia], surge la voz: el primer locutor ficticio de la literatura gauchesca es el gaucho en tanto cantor y patriota. La voz, el registro, aparece escrita, hipercodificada y sujeta a una serie de convenciones formales, métricas y rítmicas; pasa ella también por una institución disciplinaria, la poesía escrita, como el gaucho por el ejército, y se transforma en signo literario" (p. 23).

2 Tal vez sea esto lo que hace decir a Renzi que Borges debe ser leído como la clausura (al interior del sistema) de la literatura argentina del siglo XIX (PIGLIA, 2008, p. 132). 
complejizada. Lo que resulta problemático en su formulación son los presupuestos esencialistas que se esconden detrás de la idea de "fuentes creativas y espontáneas de la población" (RAMA, 1980, p. 9) a la que alude el autor para dar cuenta del más acá de la imposición autoritaria de la cultura modernista. Como corolario de esta posición, cabría esperar del analista que interprete otras culturas como si fueran mundos distantes, antes de la mácula modernizadora. Difícil resulta adoptar un planteo semejante en nuestros días, luego de la crítica de la ingenuidad inicial de los planteos objetivistas en los análisis culturales. Renunciar a los supuestos que fundamentan aquella oposición no debería, claro está, dar lugar a su simétrica contrapartida.

No obstante, en la mentada contraposición entre cultura artística elevada y cultura de masas la diferenciación aún no ha sido realizada de forma convincente. Habíamos sospechado de la presuposición de una cultura de masas no mediada. Algo similar es posible decir del concepto homogéneo de una cultura de élite. Recordemos que en el planteo citado se equiparaban sin resto el proyecto político, económico y militar de la generación del ochenta con el desembarco de las ideas modernistas en la cultura latinoamericana en general y de la argentina en particular. Sin embargo, la crítica de la oposición externa entre cultura letrada y cultura oral toca también al núcleo de la primera. ${ }^{3}$ En relación con esto último es posible recordar la ideologización paradigmática de la figura del gaucho que hizo Lugones en sus conferencias de 1913 ante las autoridades nacionales. Allí una voz ajena, procedente de la cultura oral se transfigura en emblema de un xenófobo "nosotros", absolutizado como conjuro de una nueva exterioridad amenazante: la afluencia de contingentes no nativos al país (LÓPEZ, 2006).

A contrapelo de esta deriva, es posible reconstruir una segunda posibilidad, en donde las vanguardias históricas ofician acaso de modelo ejemplar. Con ellas, cobra un nuevo sentido la siguiente afirmación: "la insistencia del modernismo en su hostilidad obsesiva hacia la cultura de masas, fue cuestionado desde su origen" (HUYSSEN, 2006: pp. 5-6). Una expresión semejante admite pensar ya no en una división excluyente de la cultura de masas y de la alta cultura, sino en una división de esta división, en la cual ambos términos de la oposición aparecen como internamente desgarrados.

\section{II.- Del arte de gobernar al gobierno del arte}

sé que llegaré a ver la revolución, el salto temido / y acariciado, golpeando la puerta de nuestra desidia.

"La pura verdad", Francisco Urondo

Los movimientos de vanguardia artística han sido frecuentemente estudiados desde perspectivas diversas. Es probable que haya sido la formulación de Peter Bürger aquella que mayor solicitud ha irradiado a la hora de entender sistemáticamente la

${ }^{3}$ Al respecto, se podría sostener lo siguiente: "Renunciar a esta oposición simple no equivale a afirmar que en la cultura argentina no exista, junto con lo que hemos llamado dimensión popular, una flexión hipercultivada, cuyos contenidos ideológicos no son, por otra parte, necesariamente antipopulares" (SARLO, 1980, p. 4). 
lógica que permite abarcar casos tan distintos como las experiencias del dadaísmo, el surrealismo o el expresionismo. El autor diferencia dos tipos de críticas que es posible dirigir a la institución arte. Podemos reconocer en la historia casos de crítica inmanente al mismo sistema de producción, distribución y recepción de obras artísticas. Como ejemplo de esta modalidad de la crítica Bürger cita la disputa de los teóricos del clasicismo francés con el drama barroco. En este caso el eje de la discusión se centraba en las formas de representación legítimas del drama que se derivaban de la legitimidad de las interpretaciones del canon aristotélico. Testimonia un modo inmanente de la crítica artística, puesto que, en este caso, la división y distribución de las partes presupuestas en los esquemas de producción y recepción artísticas no eran puestos en duda. No es así con lo que se denomina crítica radical o autocrítica de la institución arte. En éste, que es el que motivó las prácticas vanguardistas, la misma separación entre arte y vida es problematizada. "La vanguardia se dirige contra ambos momentos: contra el aparato de distribución al que está sometida la obra de arte, y contra el status del arte en la sociedad burguesa descrito por el concepto de autonomía" (BÜRGER, 2000, p. 62).

El programa de las vanguardias artísticas fue, en el sentido subjetivo del genitivo, el del gobierno del arte. Adjudicándose una fuerza determinante en la capacidad de disolver los núcleos de las obligaciones normativas de la vida práctica, la cultura artística pretendió ocupar el centro desde el cual se ejerce el poder de organizar y dar sentido a la vida social. Muchas de las obras concretas realizadas por estos movimientos no carecían de aquella "flexión hipercultivada" de la que hacíamos mención más arriba $y$, sin embargo, se anclaban en un radical programa de suspensión de las distinciones -entre seriedad y juego, entre obligación y libertad, entre público y autor- que solían garantizar la estabilidad de los órdenes de la vida práctica, dejándole a la cultura artística el lugar de un mero espacio recreativo. Una curiosa afinidad entre transgresión estética y política revolucionaria marcó el imaginario de los artistas de vanguardia.

Claro que esta afinidad cobró matices diferentes dependiendo del modo de su realización concreta en las distintas experiencias nacionales. De allí que mientras que el surrealismo, el dadaísmo y el expresionismo confirmaron esta noción, el futurismo y el ultraísmo se articularon con ideologías políticas conservadoras. De la fuente de esta última experiencia bebieron los jóvenes escritores reunidos en las vanguardias literarias argentinas de los años veinte. Curiosamente, esta adopción de un interés de la cultura letrada argentina por las innovaciones formales de la práctica poética desestimó la posibilidad de motivar la práctica vanguardista en las artes con un deseo político transformador. Habrá que esperar a los años sesenta y setenta para comenzar a entrever esta alianza entre innovación estética y revolución social (SIGAL, 1991, p. 229; TERÁN, 1991, p. 129). 4

\footnotetext{
${ }^{4}$ En los términos de Juan Pablo Renzi: "Creíamos que la forma vanguardia de por sí era la que correspondía a la ideología de izquierda. Si uno quería transformaciones en el arte era porque quería transformaciones en la sociedad. Nuestra intención era desde la vanguardia tomar la ideología, no poníamos el arte al servicio de la ideología, como mero mensajero, como mera forma de transmitir mensajes, sino que tenía que ser una confluencia dialéctica, creativa y creadora de una nueva situación formal. Situación que se daría a partir de la conjunción de la actitud de vanguardia, de indagación experimental, con la actitud ideológicamente revolucionaria", en (FANTONI, 1998: pp. 58-59).
} 
Si ahora suspendemos las consideraciones históricas, constatamos que la promesa vanguardista del ascenso del arte al poder implicaba la transformación del aparato organizado detrás del gobierno tal como lo conocemos -autoridades, funciones y estructuras-. ${ }^{5}$ Ahora bien, ¿qué es gobernar? ¿Qué significa ser gobernado? El gobierno "tal como lo conocemos", el gobierno bajo su forma política, es históricamente identificable. Y en cuanto tal, el precipitado de una genealogía cuyo trazo admite ser rastreado al siglo XVI europeo. ${ }^{6}$ El gobierno es el resultado del cruce de dos movimientos en principio autónomos: el surgimiento progresivo de las estructuras administrativas de los Estados en unidades territoriales y la puesta en cuestión, desde la religión cristiana, del monopolio de la Iglesia católica en la dirección de las almas de los fieles.

En los intentos teóricos de dar respuesta a estas preguntas, es posible recorrer el itinerario que transita desde la noción de soberanía, en la cual el príncipe, para ser un buen soberano, debía buscar el bien común entendido como obediencia a la ley hasta el arte de gobernar. En este camino, el desplazamiento también se produce en los objetivos que se le asignan al gobierno. Sobre todo, el gobierno, en su nueva fundamentación, nace ante la pretensión de resolver una cuestión crucial, a saber, enfrentar el desafío de articular de manera continua el prudente gobierno del hogar y la familia con la gestión de un Estado. Sin embargo, entre el modelo de las leyes de la soberanía y el modelo de las técnicas del arte de gobernar, seguía existiendo el difícil espacio que suponía reconocer el marco demasiado amplio del primero y la estrechez y debilidad del segundo.

La superación de esta dificultad provino por el camino del nacimiento, motivado por procesos reales de expansión demográfica en el siglo XVIII, de la categoría de población. La estadística aparece en este proceso como una técnica fundamental en la producción de las condiciones de posibilidad del surgimiento de un arte de gobierno emancipado de las limitaciones del modelo económico de la familia (FOUCAULT, 1999, p. 191).

Cuando las vanguardias históricas se proponen disolver, por ejemplo, la instancia de la representación artística, en su programa se anudaba a un mismo tiempo la negación absoluta de las mediaciones entre los artistas y los espectadores $y$ las que relacionan, en las sociedades complejas, los representantes y los representados. Vale decir que el programa del gobierno del arte busca anular la distancia presupuesta en el arte de gobernar, en el ejercicio de las funciones fundamentales de todo gobierno político moderno. Esa distancia es la que separa el conjunto de funcionaros que ejercen el poder político, los gobernantes y las estructuras administrativas, y las personas que obedecen voluntariamente las decisiones tomadas por ellos. ${ }^{7}$

${ }^{5}$ Sobre el concepto de gobierno desde la ciencia política, véase: (ORLANDI y ZELAZNIK, 1995: pp. 221-261).

${ }^{6}$ Para lo que sigue, véase: "Gubernamentalidad", en (FOUCAULT, 1999).

7 El modelo estético para ello era la liberación de la materialidad de los distintos medios artísticos de las determinaciones autoritarias de un sentido: "La escena [del teatro occidental] (...) comporta, siguiendo a toda la tradición, los elementos siguientes: un autor-creador que, ausente y desde lejos, armado con un texto, vigila, reúne y dirige el tiempo o el sentido de la representación, dejando que ésta lo represente en lo que se llama el contenido de sus pensamientos, de sus intenciones y de sus ideas. (...) Esclavos que interpretan, que ejecutan fielmente los designios provisionales del «amo»". (DERRIDA, 1989, p. 322). 
Paradójicamente este proyecto, en el cual se buscaba anular la oposición entre cultura elevada y cultura de masas recurría a un minucioso trabajo formal y técnico el cual exige para su apreciación, por su misma sofisticación, un conjunto de destrezas que sólo el aprendizaje al interior de cierta condición social hace posible. Una crítica que se supo hacer a ciertas expresiones de vanguardia es que, en tanto hicieron de la innovación formal su exigencia primordial, las vanguardias presupusieron implícitamente un público informado, conformado por pares: una élite intelectual y artística apta para comprender el proyecto y su puesta en juego. En palabras de Bourdieu (1992), las vanguardias contaban con un límite interno, y éste era el de su propia conformación de clase. En algunas experiencias esto derivó, como hemos mencionado en referencia al caso argentino, en la conjugación con ideologías liberalconservadoras.

Sin embargo, no era esta la verdadera complicación que se les planteó a las experiencias de las vanguardias artísticas. Su fracaso en la transformación, incluso: en la disolución de las estructuras represivas de la vida práctica, aquello que finalmente las ha reificado en la taxonomía como históricas -y no sólo en alusión a los fenómenos de los años veinte- (GILMAN, 2003: 369 y ss.), puede ser explicado retrospectivamente en base a su posible comprensión equivocada de las obligaciones de la vida práctica. ${ }^{8} \mathrm{O}$, lo que es lo mismo, en base a lo que podría llamarse como su pasión de lo real (BADIOU, 2005). En tanto la promesa artística de una transformación de la obligación práctica en libertad estética infravaloró las determinaciones indisolubles de las regulaciones normativas de los vínculos sociales, aquella sólo pudo decepcionar en sus resultados. Ya sea porque sus producciones desnaturalizaban la radicalidad del problema inicial en obras incorporadas en el circuito de museos, currículas universitarias y otros canales institucionales de difusión artística; o bien porque, en aquellos casos en los que se fue consciente de sus límites internos, la crítica de la diferencia entre arte y vida desembocó en un abandono del primero: "[...] constatemos que una vigorosa corriente de pensamiento afirmó que era mejor sacrificar al arte que ceder en cuanto a lo real" (BADIOU, 2005, p. 167). Esta afirmación cobra un sentido pleno cuando se pasa revista al proceso de compromiso de artistas con la lucha armada a fines de los años sesenta en América Latina. Haroldo Conti y Rodolfo Walsh representan quizás los casos más conocidos. El resultado trágico de esta táctica también lo es. ${ }^{9}$

La única novela publicada por Paco Urondo, Los pasos previos ([1972] 2011), narra este movimiento de progresiva incorporación de los intelectuales y artistas a la lucha revolucionaria en Argentina. Pero, lo que es más interesante para nuestra discusión, lo hace de un modo en que ese contenido narrado es replicado en su

\footnotetext{
8 "En lo que respecta al programa transgresor de la vanguardia, se puede decir que está culturalmente determinado y que está ligado históricamente a un modelo productivista (como cuando alude a un "cambio del aparato") que se corresponde con una concepción simplista de la ideología que la considera como una mera codificación de creencias de clase (como cuando pretende "transgredir las convenciones"), y con una liviana idea del arte como instrumento de cambio revolucionario" (FOSTER, 2003, p. 174).

9 "El golpe militar de 1976 y la dictadura quebraron cualquier ilusión de una teleología en cuyo vértice vendrían a fusionarse la transgresión estética y la revolución política" (OUBIÑA, 2011, p. 53).
} 
construcción formal. Efectivamente, esta novela aparece como documento histórico en donde es posible seguir término a término los vaivenes de la radicalización de la lucha política entre los años sesenta y los años setenta. Y lo hace con la virtud de una voz que sabe de lo que testimonia puesto que vive lo que dice. Sin embargo, Los pasos previos se reconoce como un texto experimental, y pretende hacer de la renovación de las formas de producción literarias un paso previo de la revolución social. Es por ello que, si bien la novela tiene un autor que la firma, su composición desmiente la autoridad de una figura de autor. En efecto, sabemos que el texto se compone al modo de un collage en el que se incorporan fragmentos de notas periodísticas de Pedro Leopoldo Barraza sobre el caso Vallese, al tiempo que se introducen comentarios de Rodolfo Walsh y segmentos de Sólo el pueblo salvará al pueblo de Raimundo Ongaro. En la configuración de estos materiales heterogéneos, la novela objeta su finición estructural y pretende volverse otra cosa.

Otro modo de volverse otra cosa resulta de la producción de estrategias artísticas orientadas a desdecirse a sí mismas. Desdecirse a sí mismas significa aquí afirmar una pretensión, en principio infinita, de transgresión del límite que separa al arte de aquello que no lo es, pretensiones semejantes en radicalidad a las planteadas por las vanguardias; y luego, o mejor: a su vez, hacer visible su incapacidad para realizarlas efectivamente..$^{10}$ Así, se hace uso de la búsqueda vanguardista de negar la especificidad de lo literario, pero esa búsqueda se disuelve allí donde se reafirma esa especificidad precisamente por aquella negación.

Lo que parecen hacer evidente estas prácticas, puestas en juego en nuestro presente, es un fuerte tono auto-reflexivo. Si bien es cierto que las prácticas vanguardistas no carecían de esta dimensión acerca de los conflictos internos al vínculo del arte con la vida política de la sociedad, ella era supeditada al horizonte de resolubilidad de esas tensiones en la disolución revolucionaria de las diferencias constitutivas de la modernidad capitalista. Baste recordar una de las tantas escenas de Los pasos previos, en la cual un grupo de artistas se plantea el objetivo de convertirse "en verdaderos renovadores del teatro argentino". El foco del debate se centra en los medios más adecuados para la expresión artística de una verdad política. ¿Qué estrategia retórica adoptar allí donde el artista reconoce su "responsabilidad frente al público y frente al teatro nacional"? Pero sobre todo, de qué modo sortear los obstáculos de la censura y la represión que ofrecen a la libre producción de una verdad revolucionaria. Como sostiene el personaje de Simón, "hay una realidad, y esa realidad tiene sus límites, además de sus reglas de juego" (p. 36).

Sin embargo, esta conciencia del límite era conjurada por la certeza artística de un advenimiento -recordemos el tono esperanzado del "sé que llegaré a ver" del poema "La pura verdad"-. La revisión de los límites de lo real es el paso previo, el anuncio de un futuro indiscernible:

"-¿Y vos sos el que querés hacer la revolución?

-Me gustaría.

${ }^{10}$ Estamos pensando, por ejemplo, en la significación de la publicación de El entenado al interior de la obra experimental de Juan José Saer. Para esto, véase: (PREMAT, 2004). 
-¿Y para qué?

-Para escribir; para escribir poemas.

-Y por el hombre y la injusticia, ¿no?

-Sí, por supuesto. Pero también para escribir poemas.

-No sabía que escribías poemas.

-No escribo, voy a escribir, cuando se haga la revolución" (p. 37).

A diferencia de la convicción que motiva el vuelco de Mateo a la lucha armada y a su sacrificio final, esta ausencia de ingenuidad funciona en los planteos de las experiencias artísticas contemporáneas como una reflexión de su propio lugar luego del fracaso de la promesa vanguardista en el concierto de las prácticas culturales de las sociedades actuales. Al hacerlo, son al mismo tiempo post-vanguardistas y metavanguardistas. Puesto que se reconocen como prácticas artísticas que ya no pueden compartir un horizonte de sentido con el imperativo de las experiencias de vanguardia, identifican su presente como irreductible. Pero en la medida en que no desisten de articular una práctica crítica de las formas tecnificadas de la cultura contemporánea, en donde aún siga siendo posible un distanciamiento de las maneras de sometimiento cultural y violencia simbólica que imperan en las actuales democracias latinoamericanas, se ven impelidas a realizar una indagación y una investigación en los procedimientos que caracterizaron a los movimientos de vanguardias, repitiéndolos en varios casos aunque siempre, como toda repetición, con una mínima e infinitesimal diferencia (Cfr. MENKE, 2008). Recuperar en la actualidad la orientación práctica de las experiencias históricas de las vanguardias de los años sesenta y setenta supone volver a plantear la pregunta por el orden social justo y por las prácticas y decisiones individuales y colectivas que le darían sustento.

\section{Los conflictos político-culturales de la idea de justicia}

Cuando se busca responder a este interrogante se reconoce la dificultad de enunciar positivamente esas pretensiones artísticas de justicia. Para ello la crítica cultural requiere de un discurso subsidiario que la asista en su tarea. Consecuentemente, la crítica cultural requiere desplazar el eje de la discusión del análisis de los procedimientos formales que estructuran las prácticas de la cultura artística hacia los planteos político-culturales de la teoría de la justicia. La clarificación de las dimensiones, no necesariamente coincidentes entre sí, de la idea de un orden social justo presente en las prácticas artísticas innovadoras, aunque no formulada explícitamente, nos permitirá comprender adecuadamente el sentido normativo del descontento artístico con las formas de injusticia.

En nuestros días es posible distinguir, al interior de los fenómenos de protesta, dos modos de reivindicación de justicia por parte de los actores sociales. Uno de ellos podría ser entendido como aquellas formas de movilización que reclaman una distribución más justa de los recursos y la riqueza. Los conflictos salariales, las reivindicaciones de redistribución entre las zonas más pobres y las más ricas de un país, por nombrar solamente algunas de ellas, forman los casos más emblemáticos de este tipo de pretensiones de justicia social. Este modelo, teórico y práctico, se centra 
en injusticias que define como socioeconómicas y asume que las mismas están ancladas en la estructura socio-económica. Los sujetos colectivos de la injusticia serían clases o colectividades que definen su identidad por la posición que ocupan en la estructura social y en relación con el mercado. Junto a ellos es posible observar de un modo cada vez más frecuente un segundo tipo de petición de justicia social que hace de la lucha por el reconocimiento de identidades culturales su motivo central. Si en el primer modo del conflicto social los grupos aspiran a una justa -lo que equivale a decir: a una equitativa- distribución del ingreso, en esta segunda forma los grupos en lucha aspiran a un mundo en que se acepte la diferencia, "en el que la integración en la mayoría o la asimilación de las normas culturales dominantes no sea ya el precio de un respeto igual" (FRASER y HONNETH, 2006, p. 17). Los ejemplos que aquí se discuten son los de las reivindicaciones de minorías sexuales, de género, étnicas, etc. Se entiende así por qué el objetivo de máxima del primer paradigma es la lucha por la abolición de las diferencias de grupo mientras que, en el segundo modelo, trata las diferencias en dos sentidos: o bien reconociéndolas y celebrándolas o bien deconstruyendo los términos dualistas que las constituyen jerarquizándolas.

Sin embargo el descentramiento de las reivindicaciones de redistribución igualitaria ha conducido a un efecto no deseado: la disociación -incluso, la polarización- de ambas demandas. Como si ellas sólo admitiesen ser pensadas como mutuamente excluyentes. En consecuencia, tanto en el plano de los actores como de las teorías que aspiran a justificar normativamente los objetivos que motivan las acciones de lucha, se ha producido un "distanciamiento generalizado de la política cultural respecto de la política social y el de la política de la diferencia respecto de la política de la igualdad" (FRASER y HONNETH, 2006, p. 18). ¿De qué manera resolver esta antítesis? El desafío entonces en nuestros días es ofrecer un marco de análisis y de acción que sea capaz de articular ambas instancias.

Este enfoque sostiene como tesis que las diferenciaciones sociales entre grupos son, en ambos casos, bidimensionales. Por lo tanto, sería erróneo concebir una pureza en los sometimientos de grupos explotados económicamente o de grupos menospreciados en sus identidades culturales. En cada fenómeno de injusticia se observa la presencia, en mayor o menor medida según el caso, de una determinación económica y de una cultural. Como ejemplo, Fraser -quien sostiene esta hipótesispropone a las injusticias del racismo. En la economía es posible detectar cómo la categoría "raza" organiza divisiones entre trabajos remunerados serviles y no serviles o entre fuerza laboral explotable y "superflua". Las minorías étnicas padecen con frecuencia el trabajo servil o altos niveles de pobreza. Como consecuencia, sufren de injusticias económicas que exigen ser paliadas por políticas redistributivas. Al mismo tiempo, estas minorías étnicas son víctimas de oposiciones clasificatorias, como las de "blanco" y "negro", las cuales terminan por estigmatizar su identidad cultural.

Esas normas eurocéntricas, institucionalizadas de un modo generalizado, producen formas racialmente específicas de subordinación de estatus, que incluyen la estigmatización y la agresión física; la devaluación cultural, la exclusión social y la marginación política; hostilidad y menosprecio en la vida cotidiana y negación de los derechos plenos y protecciones equiparables de los ciudadanos (FRASER y HONNETH, 2006, p. 31). 
Frente a semejantes fenómenos se hace necesaria la implementación de políticas de reconocimiento.

Esta concepción bidimensional de la justicia asume como núcleo normativo la noción de "paridad de participación". Semejante criterio permitiría evaluar cuándo una reivindicación de justicia pasa la prueba de su legitimidad. Pues no todas las peticiones de justicia son admisibles. Las identidades racistas, claramente, no merecen un reconocimiento de su "singularidad" cultural puesto que en su misma configuración anulan la posibilidad de que otros participen en la vida social en calidad de igualdad. Según Fraser deben cumplirse dos condiciones para que las pretensiones de un grupo social sean consideradas como justas: que la distribución de los recursos materiales garanticen la "voz" independiente de todos los participantes; y que los valores culturales institucionalizados expresen el mismo respeto a todos los participantes.

Del primer requisito se sigue que serán consideradas injustas aquellas reivindicaciones de grupos que aspiran a acaparar una gran porción de la renta, mientras que del segundo se sigue que se les negará las pretensiones de reconocimiento a aquellos grupos que aspiren a institucionalizar valores excluyentes que nieguen la estima a otras personas. Se espera de esto que frente a ambos casos un Estado democrático de derecho negaría sus pretensiones de justicia. Ahora bien, cabría formular la siguiente pregunta en el contexto de nuestra indagación: ¿qué lugar le cabe a las prácticas artísticas experimentales en esta concepción de la justicia?

En principio, según lo que hemos podido observar más arriba, la innovación artística adopta inevitablemente un estatuto minoritario al interior de las formas culturales del mundo contemporáneo. Nos situamos en un tiempo post-vanguardista, en donde las prácticas artísticas que se pretenden innovadoras ya no cuentan con las pretensiones infinitas de las experiencias radicalizadas. Por lo tanto, esta pregunta debe ser determinada a partir de un conocimiento exacto del sentido de las experimentaciones artísticas en la actualidad.

Sería adecuado precisar la pregunta en un doble sentido. Primero, ¿es correcto evaluar como legítimas sus reivindicaciones de reconocimiento ${ }^{11}$ Luego de las discusiones sobre la violencia ejercida en los binarismos evaluativos entre arte elevado y cultura de masas, ¿cómo entender la especificidad de prácticas culturales minoritarias en las que se transgreden los hábitos y los cánones recibidos? Si bien conocemos experiencias políticas en las cuales se les ha otorgado un reconocimiento estatal a la diferencia artística, es cierto también que muchas veces éste ha operado de un modo pasivo. Lo que equivale a decir: un reconocimiento sin traducción en políticas de promoción.

\footnotetext{
${ }^{11}$ En un sentido levemente distinto, aunque apuntando a la misma cuestión, Sergio Raimondi ha planteado esto con incomparable precisión: "...una política cultural propiamente dicha debería poder hacer formar parte de su agenda temas que, en un a priori verosímil, parecerían ajenos o más apropiados para una secretaría de gobierno o de planificación. (...) En el marco de una operatoria general sobre una ciudad, poder sostener con justificación la pertinencia de un programa cultural frente a la urgencia de $\mathrm{x}$ cantidad de cuadras de asfalto, la inauguración de un plan de viviendas o el equipamiento de una unidad sanitaria, es un desafío más que atendible. Yo mismo tengo que revisar día a día la propiedad de un hecho cultural frente al conjunto de los problemas de la ciudad. Y justamente el tema es que ningún programa cultural debería considerar ajeno a su ámbito ni las cuadras de asfalto, ni el plan de viviendas ni el ámbito cotidiano de una unidad sanitaria", (VV. AA., 2013, p. 77).
} 
Esto se ha justificado por el carácter precisamente minoritario y poco redituable al que en muchos casos queda reducida la práctica artística experimental. Curiosamente, la ausencia de públicos masivos para estas prácticas las ha colocado en una situación semejante al lugar periférico en el que fueron situados sus presuntos casos opuestos en los años de gobiernos neoliberales en la región. Nos referimos a ese conjunto de prácticas, creencias, rituales y celebraciones que forjan el patrimonio de las culturas populares (MÍGUENZ y SEMÁN, 2006). En comparación con otras actividades más redituables para el desarrollo económico y social, tanto las expresiones de las culturas populares como las prácticas artísticas con pretensiones innovadoras se vuelven objetos privilegiados de la marginación. Una exclusión semejante, como contrapartida, ha motivado en la historia de las prácticas artísticas sentimientos elitistas de desprecio hacia los fenómenos de la cultura de masas. ${ }^{12} \mathrm{~A}$ su vez, también hemos podido demostrar el carácter crítico de las prácticas experimentales, incluso luego del fracaso del programa de las vanguardias históricas, mediante el tipo de efecto de descentramiento que establecen con las identidades, de sí mismas en cuanto fenómenos culturales y de quienes las aprecian.

De esto se sigue otra cuestión a responder, relativa a la segunda dimensión de la concepción de la justicia antes referida, a saber: ¿es legítimo, desde el punto de vista de un Estado democrático de derecho, considerar como justas aquellas reivindicaciones de redistribución de los recursos expresadas por estos fenómenos innovadores? (SEEL, 2003) Son conocidos los fenómenos de extrema inequidad en el campo artístico, de donde muchas personas y grupos terminan viviendo, parafraseando a Weber, para y no del arte. ${ }^{13}$ Como primera consecuencia, los artistas se ven obligados a desarrollar trabajos ajenos al mundo artístico para asegurar sus medios materiales de subsistencia. ${ }^{14}$ Como segunda consecuencia, las posibilidades de lograr una carrera exitosa vienen dadas por la herencia de fortuna de familias posicionadas económicamente (BOURDIEU, 2012).

En la medida en que no se reconoce al trabajo artístico como una actividad remunerativa, no cuentan con un aparato legal consistente que garantice sus derechos laborales. Evidentemente, la cuestión se decide en la definición de lo que es, y de lo que no es, una práctica artística. Pues de esto depende que incluso aquellos que realicen una carrera artística sin el apoyo económico de la familia de la que provienen

12 "Los artistas van a marcar su oposición a los burgueses por la reivindicación de esta marginalidad que les ha devaluado a los ojos de aquellos: saltimbanquis, extranjeros, pelicanos, albatros, lobos... las metáforas poéticas abandonadas para decir su diferencia, pero una diferencia que hace a su grandeza. [...] El artista afirma su orgullo aristocrático de un ser cuyo don de nacimiento suprime y eleva por encima del común de los mortales en una concepción renovada de la nobleza" (CHIAPELLO, 2000, p. 41 -trad. nuestra).

13 Esta condición no ha resultado ajena a la misma producción artística: en la novela El pozo y las ruinas (NÉSPOLO, 2011) la narración coloca al escritor proletarizado en el contexto de una redacción de un "megamedio concentrado". El devenir redactor del escritor es el proceso de reducción de su búsqueda poética a la fungibilidad universal del mercado. Un ghost writer no puede sino contar con una condición de segundo: como corrector de una escritura original, como redactor cuya firma será la de otro. En la novela, el personaje del redactor, llamado Manuel Reinoso, ocupa estructuralmente este lugar

${ }^{14}$ Conocidos son los casos de Juan L. Ortiz, quien trabajó hasta jubilarse de empleado público, o de Roberto Arlt, quien se desempeñara como cronista policial en el periódico Crítica. Esto no significa, claro, que esta condición sea un impedimento para volverse en tanto tal una fuerza productiva (KIERNAN, 2007). 
cuenten, o no, con una jubilación en su vejez (FRIERA, 2011). En consecuencia, nos encontramos con dos obstáculos, tanto en términos de redistribución como de reconocimiento, que dificultan la posibilidad de entender socialmente como legítimas las reivindicaciones de justicia de las prácticas artísticas. No obstante, como hemos podido observar, este rechazo social conlleva consecuencias claramente injustas para con los grupos que desempeñan tareas en este ámbito. Esta tensión aparece como un conflicto invisible para las políticas culturales si lo percibimos o bien desde las categorías del universalismo jurídico o bien del particularismo de los valores culturales. ${ }^{15}$ Como en la situación que planteaba Raimondi, para determinar su sentido, es preciso no desestimar ni a las exigencias de reconocimiento (poesía) ni a las peticiones de justicia distributiva (prosa administrativa). Pero hemos constatado, también, que ambos son mutuamente excluyentes. Intentemos seguir este campo de fuerzas en tensión a partir de un ejemplo concreto.

Precisamente frente al déficit de una redistribución justa de la riqueza para con aquellos que realizan prácticas artístico-literarias, en 2011 se ha presentado en distintas Comisiones de la Cámara de Diputados de la Nación argentina un proyecto de ley que busca reglamentar la práctica de escritura de autores literarios, otorgando el derecho a poetas, narradores, cuentistas y novelistas a ser incluidos en el sistema previsional. Con el apoyo de la Sociedad Argentina de Escritores y de más de mil personalidades de la cultura, los avances incalculables que supone la posibilidad de una discusión sobre la condición laboral de la práctica artístico-literaria son innegables. La conquista que supone incluir esta problemática en la agenda de la esfera de discusión democrática, tanto legislativa como extra-estatal, abre un camino de reflexión política sobre los monopolios que rigen el mercado editorial que, provechosamente, no tendrá fin. En esta abertura quisiéramos situarnos.

Una de las dimensiones de este nuevo debate consiste en el momento dilemático en el que necesariamente se ve enfrentado el proyecto, cuando de lo que se trata es de activar los presupuestos del diseño de cualquier política pública; a saber: la tarea de delimitar el campo de aplicación del universo de beneficiarios posibles. Este recorte lo brinda la definición del universo y es en su precisión que descansa el trazado del borde que incluye y excluye a sus actores (DWORKIN, 1982). Una ley es aplicable allí donde los casos de la aplicación pueden ser percibidos como homogéneos desde la perspectiva de la ley. Aquí nos referimos al proceso de interpretación y selección de la población destinataria de esta legislación laboral: ¿quién es un escritor literario? ¿A partir de cuándo se es un escritor literario? ¿Dónde termina su labor?

\footnotetext{
"Se entiende por escritor literario a toda persona que desarrolle el uso de la palabra escrita como profesión y que trabaje con ese instrumento de modo profesional y artístico, dentro de los distintos tipos de géneros reconocidos a las composiciones literarias, como ser poesía, narrativa, ensayo y dramaturgia, en sentido amplio".
}

${ }^{15}$ En este sentido, cfr. las objeciones que expresa Axel Honneth a la teoría de la justicia de Fraser: "Redistribución como reconocimiento: Respuesta a Nancy Fraser", en (FRASER y HONNETH, 2006: pp. 92-100). 
Esos límites, aun cuando se los concibe "en sentido amplio", no dejan de hacer sentir su eficacia.

El proyecto presenta varios requisitos para adherir al régimen creado por la ley. Aquí nos interesan aquellos reunidos en el artículo 7, inciso c, en donde la figura del escritor cobra relieve. El interesado deberá: "Acreditar una trayectoria pública y constante en la creación literaria no inferior a veinte años o haber publicado cinco libros de creación propia o diez incluyendo coautoría artística...". El estatuto de realidad de los méritos y antecedentes de un escritor literario pueden no ser parte de una puesta en duda, no así el valor de los mismos. Para ello, el proyecto (Artículo $13^{\circ}$ ) contempla una Comisión de Evaluación Ad Honorem de cuyo seno cabría esperar un legítimo juicio, "sin análisis de mérito literario, pero sí de ponderación del esfuerzo y la construcción social". Sin embargo, no queda del todo claro cuáles son los estándares de enjuiciamiento que deberían ser usados a la hora de realizar la selección de los beneficiarios. ¿Basta con hacer uso de un criterio numérico? ¿Es determinada cantidad de libros publicados la justificación más adecuada para trazar el corte entre un autor que ha aportado a la cultura nacional y una persona que no puede ni siquiera ser reconocida como autor? ¿Qué hacer con aquellos escritores reconocidos por el público y por los aparatos de consagración que han publicado sólo un libro en sus vidas? ¿Y si el "autor" es un autor apócrifo? ¿Y si es inédito? La historia de la crítica textual nos ofrece sendos ejemplos de esta espesura, difícil de zanjar mediante la voluntad de una decisión. ${ }^{16}$

Ahora bien, es importante entender el sentido de la dificultad de plantear positivamente los criterios de evaluación de parte de los miembros de ese jurado. En efecto, consideramos que esa dificultad no revela tanto una supuesta falla en la redacción de un proyecto de ley; sino, por el contrario, muestra el nervio opaco que subyace al vínculo entre la dinámica de la práctica artística con la lógica de decisión de las instituciones administrativas y la lógica discursiva de la esfera pública democrática.

Decir que en la regulación legislativa del arte se hace visible un núcleo dilemático significa decir que ni la deconstrucción de la postulación de un órgano de autoridad injustificada en lo que hace a su juicio de gusto puede obliterar la necesidad y el derecho social de todo trabajador al reclamo por una justa distribución de la riqueza; ni la lucha por la redistribución de los bienes en términos de sistema de seguridad social puede oscurecer los impasses irreductibles de las luchas por el reconocimiento de parte de la práctica artística innovadora. El gobierno del arte se enfrenta al dilema de un diálogo entre lenguajes inconmensurables.

\footnotetext{
${ }^{16}$ El carácter abierto de estas preguntas se manifiesta con crudeza allí donde la prosa del mundo se vuelve dependiente de la "originalidad" de la prosa de una obra. En estos casos problemáticos la identidad del autor no garantiza su autoridad sobre la identidad de su obra: los jueces pierden su apariencia de neutralidad y afirman su calidad de partes en el conflicto. Ilustrativos resultan los litigios por "plagio" en concursos literarios como los acaecidos recientemente en Argentina (LIBERTELLA, 2007).
} 


\section{Hacia un gobierno democrático del arte}

Formulemos a partir de nuestro recorrido algunos interrogantes en lo que respecta al vínculo entre prácticas artísticas y políticas públicas de la cultura. Los fenómenos analizados en este escrito van de la mano de la siguiente encrucijada. Dados los recursos limitados con los que cuenta la administración pública, la justicia distributiva debería tener en cuenta una multiplicidad de determinaciones extraculturales que harían posible políticas culturales democráticas. Entre ellas, los necesarios arreglos institucionales que persiguen crear estructuras de oportunidades e impedir que los mismos sean objeto de manipulaciones monopólicas (Cfr. BRUNNER, 1987, p. 198). Pero también, y fundamentalmente, la intervención en los desequilibrios preexistentes mediante la promoción del acceso a la apreciación de bienes simbólicos por parte de amplios sectores históricamente relegados en nuestra región. Frente a este imperativo, ¿no merecería ser entendida como antidemocrática una pretensión de distribución de recursos que refuerce la actual situación de desigualdad social en el acceso a los bienes culturales realmente existentes? Ahora bien, ¿no es posible reconocer también una desigualdad social en las posibilidades sociales de innovación cultural? La diferencia que presentan estos últimos interrogantes evidencia un genuino problema para el estudio y la práctica de las políticas culturales en la actualidad.

Sólo una ampliación de derechos en relación con la participación igualitaria en la esfera pública hará posible la discusión colectiva de los valores que merecen ser institucionalizados en el diseño y aplicación de las políticas públicas. Estos valores en disputa son, finalmente, aquellos que orientan el sentido de las políticas destinadas a la cultura artística. Un gobierno democrático del arte, en el sentido objetivo del genitivo, implicaría la posibilidad de una acción política que sea consciente de la continua diferencia que tensiona las reivindicaciones artísticas por la justicia. Implicaría, en los términos de Raimondi, una prosa administrativa que contenga esa diferencia. La diferencia entre los reclamos por el reconocimiento del carácter democrático del valor estético de la experimentación, y las peticiones por una redistribución equitativa de los recursos económicos y simbólicos.

Estos son los retos fundamentales ante los que el concepto de las políticas culturales es situado por el caso de la cultura artística. El pasaje por su experiencia muestra que las luchas sociales por la justicia que motivan el diseño de políticas culturales no se pueden situar meramente en la fácil oposición entre redistribución y reconocimiento. Por el contrario, se encuentra de nuevo en debate determinar qué son las políticas culturales. 


\section{Bibliografía}

BADIOU, Alain. El siglo. Buenos Aires: Manantial, 2006

BORGES, Jorge L. El tamaño de mi esperanza. Buenos Aires: Seix Barral, 1993.

BOURDIEU, Pierre. Les Règles de I' art: genèse et structure du champ littèraire. Paris: Editions du Seuil, 1992.

BOURDIEU, Pierre. La distinción. Buenos Aires: Taurus, 2012.

BRUNNER, José J. "Políticas culturales y democracia: hacia una teoría de las oportunidades". In: GARCÍA CANCLINI, Néstor (comp.). Políticas culturales en América Latina. México: Grijalbo, 1987.

BÜRGER, Peter. Teoría de la vanguardia. Barcelona: Península, 2000.

CHIAPELLO, Eve. Artistes versus managers: le management culturel face à la critique artiste. Paris: Editions Métailié, 1998.

DALMARONI, Miguel. Una república de las letras. Rosario: Beatriz Viterbo, 2006. DERRIDA, Jacques. La escritura y la diferencia. Barcelona: Antropos, 1989.

DWORKIN, Ronald. Law as Interpretation. In: Texas Law Review, v. 60, 1982.

FANTONI, Guillermo. Arte, vanguardia y política en los años 60: conversaciones con Juan Pablo Renzi. Buenos Aires: El cielo por asalto, 1998.

FOSTER, Hal. "Recodificaciones: hacia una noción de lo político en el arte contemporáneo". In: VV. AA. Modos de hacer: arte crítico, esfera pública y acción directa. Salamanca: Ediciones Universidad de Salamanca, 2003.

FOUCAULT, Michel. Obras esenciales. V. III. Barcelona: Paidós, 1999.

FRASER, Nancy y HONNETH, Axel. ¿Redistribución o reconocimiento? Un debate político-filosófico. Madrid: Morata y Fundación Paideia-Galiza, 2006.

FRIERA, Silvina. "Ser escritor, ser artista, vuelve a tener peso y valor". In: Página 12. Buenos Aires, 11 de abril, 2011.

GILMAN, Claudia. Entre la pluma y el fusil. Buenos Aires: Siglo XXI, 2003.

HALL, Stuart. "El espectáculo del "Otro"'". In: Sin garantías: trayectorias y problemáticas en estudios culturales. Popayán/Lima/Quito: Envión Editores/IEP/Instituto Pensar/Universidad Andina Simón Bolivar, 2010.

HUYSSEN, Andreas. Después de la gran división: modernismo, cultura de masas, posmodernismo. Buenos Aires: Adriana Hidalgo, 2006.

KIERNAN, Fernando. "Roberto Arlt: periodista". In: Contorno. Edición facsimilar, n. 2. Buenos Aires: Ediciones Biblioteca Nacional, [1954] 2007.

LIBERTELLA, Mauro. "Historias dos veces contadas". In: Página 12, Buenos Aires, 27 de mayo, 2007. 
LÓPEZ, María Pía. Lugones: entre la aventura y la cruzada. Buenos Aires: Colihue, 2004.

LUDMER, Josefina. El cuerpo del delito. Buenos Aires: Libros Perfil, 1999.

LUDMER, Josefina. El género gauchesco: un tratado sobre la patria. Buenos Aires: Libros Perfil, 2000.

LUGONES, Leopoldo. El payador. Buenos Aires: Ediciones Centurión, 1944.

MENKE, Christoph. "Promesa e impotencia de la representación teatral". In: La actualidad de la tragedia. Madrid: La balsa de la Medusa, 2008.

MÍGUENZ, Daniel y Semán, Pablo (ed.). Entre santos, cumbias y piquetes: las culturas populares en la Argentina reciente. Buenos Aires: Biblos, 2006.

NÉSPOLO, Jimena. El pozo y las ruinas. Barcelona: Los libros del lince, 2011.

ORLANDI, Hipólito y ZELAZNIK, Javier. "El Gobierno". In: PINTO, Julio (Comp.).

Introducción a la ciencia política. Buenos Aires: Eudeba, 1995.

OUBIÑA, David. El silencio y sus bordes: modos de lo extremo en la literatura y el cine. Buenos Aires: FCE, 2011.

PIGLIA, Ricardo. Respiración artificial. Barcelona: Anagrama, 2008.

PREMAT, Julio. La dicha de Saturno: escritura y melancolía en la obra de Juan José Saer. Rosario: Beatriz Viterbo, 2004.

PRIETO, Adolfo. El discurso criollista en la formación de la Argentina moderna. Buenos Aires: Sudamericana, 1988.

RAMA, Ángel. "Argentina: crisis de una cultura sistemática". In: Punto de vista, III, No 9, 1980.

RAMA, Ángel. La ciudad letrada. Montevideo: Arca, 1998.

SARLO, Beatriz. "La literatura de América Latina. Unidad y conflicto". In: Punto de vista. III, N॰8, 1980.

SELL, Martin. "Entre la recaudación y el distanciamiento. Cuatro estudios de caso sobre cultura de masas". In: Adornos Philosophie der Kontemplation. Frankfurt: Suhrkamp, 2003.

SIGAL, Silvia. Intelectuales y poder en la década del sesenta. Buenos Aires: Puntosur, 1991.

TERÁN, Oscar. Nuestros años sesenta. Buenos Aires: Puntosur, 1991.

URONDO, Francisco. Los pasos previos. Buenos Aires: Adriana Hidalgo, [1972] 2011.

VV.AA. "Entrevista a Sergio Raimondi", In: Mancilla, № 5, 2013. 
Title: Art's government. Current problems of cultural policies

Abstract: In this paper we seek to analyze the present existing relation between artistic culture and cultural policies in some Argentinean Literature's phenomenon. We ask about the theoretical ways in which the State has tried to regulate the artistic practice and, simultaneously, about the types of reaction from its addressee. As we consider that an abstract approach would be unable to access to the complexities of the different possible experiences, we have made an approach to the historical precedents of the relationship between the artistic practices and the design and implementation of public policies in two periods: the conformation of the State at the end of 19th century (I) and in the time of the avant-gardes from the sixties and seventies (II). This trail will allow us to reconstruct a theoretical approach to the underlying conflicts of the idea of justice in the State - literary practices debate (III). At the end of the paper we refer to some consequences from these historical experiences for the study of the current challenges of a democratic government of the artistic culture (IV).

Keywords: Artistic Culture, Cultural Policies, Social Justice, Argentinean Literature, State

Recebido em: 07/09/2013. Aceito em 30/11/2013 